\title{
The Role of Pulse Oximetry as a Screening Tool for Early Detection of Critical Congenital Heart Disease in Newborn
}

Section: Healthcare ISI Impact Factor (2019-20): 1.628 IC Value (2019): 90.81 $\operatorname{SJIF}(2020)=7.893$

\author{
M. A. Mannan' ${ }^{1}$ Amlendra Yadav'2, Tareq Rahman², Ismat Jahan³, \\ Sadeka Choudhury Moni ${ }^{3}$, Mohammad Abul Khayer ${ }^{4}$, \\ Mohammad Kamrul Hassan Shabuj ${ }^{5}$, Sanjoy Kumer Dey', \\ Mohammod Shahidullah ${ }^{6}$
}

\begin{abstract}
'Professor, Department of Neonatology, Bangabandhu Sheikh Mujib Medical University, Shahbag, Dhaka, Bangladesh; 'Neonatologist, Bangabandhu Sheikh Mujib Medical University, Shahbag, Dhaka, Bangladesh; ${ }^{A}$ Assistant Professor, Department of Neonatology, Bangabandhu Sheikh Mujib Medical University, Shahbag, Dhaka, Bangladesh; ${ }^{4}$ Assistant Professor, Department of Pediatrics, Mugda Medical College \& Hospital, Dhaka, Bangladesh; ${ }^{5}$ Associate Professor, Department of Neonatology, Bangabandhu Sheikh Mujib Medical University, Shahbag, Dhaka, Bangladesh; ${ }^{6}$ Professor and Chairman, Department of Neonatology, Bangabandhu Sheikh Mujib Medical University, Shahbag, Dhaka, Bangladesh.
\end{abstract}

\section{ABSTRACT}

Introduction: Early diagnosis of critical congenital heart defects (CCHD) may be missed both during prenatal echocardiography and the short stay in the neonatal nursery, leading to circulatory collapse or death of the newborn before readmission to hospital. Pulse oximetry screening (POS) has been proposed as an effective, non-invasive, inexpensive tool allowing earlier diagnosis of critical congenital heart disease (CCHD).

Objective: This study was conducted to find out the role of pulse oximetry as a screening tool for early detection of critical congenital heart disease in newborn.

Methodology: This prospective study was conducted in department of Neonatology and department of Obstetrics \& Gynaecology, Bangabandhu Sheikh Mujib Medical University, Shahbag, Dhaka, Bangladesh a tertiary care hospital over one year. All inborn and outborn newborns stayed in hospital within 24 hours of age were included in this study. After taking written informed consent from parents, a thorough history was taken by investigator. Then pulse oximeter was used in standard way to measure reading from arms and legs. Interpretation and follow-up by Echocardiogram was done in pre-designed criteria. Data were calculated manually.

Results: During the study period a total of 1033 newborn babies were screened. Among screened newborn positive screening rate was found $16(1.5 \%)$ cases. Newborns with positive screening were advised to do echocardiographic evaluation. Echocardiography was done in all 16 babies and 4 newborn babies were having critical congenital heart diseases. This present study found sensitivity, specificity, PPV and NPV of pulse oximetry screening $100 \%, 99.6 \%, 25 \%$ and $100 \%$ respectively. On echocardiography critical congenital heart diseases were double outlet right ventricle, tetralogy of fallot, pulmonary stenosis and d-TGA.

Conclusion: The present study concluded that with this high sensitivity, specificity and negative predictive value Pulse oximetry is safe, feasible and may be wont to screen for critical congenital heart condition. It would be an attainable noninvasive method to detect the congenial heart disease along with the physical examination in newborn.

Key Words: Pulse Oximetry Screening, Critical Congenital Heart Disease, PPV, NPV Of Pulse Oximetry, Tetralogy Of Fallot, Pulmonary Stenosis And D-TGA

\section{INTRODUCTION}

Critical congenital heart defects (CCHD) occur in 2-3 per 1000 live births, usually require invasive medical intervention within the first month of life and can lead to death or sig- nificant morbidity if not diagnosed in a timely manner. ${ }^{1}$ Early detection is important for reducing mortality and improving the postoperative outcome. ${ }^{2}$ In United States, a survey by American Heart association found congenital cardiovascular defects were the most common cause of infant death. ${ }^{3}$ Criti-

Corresponding Author:

Dr. M A Mannan, Professor, Department of Neonatology, Bangabandhu Sheikh Mujib Medical University, Shahbag, Dhaka, Bangladesh. Email: drmannan64@gmail.com

ISSN: 2231-2196 (Print)

Received: 02.08 .2021
ISSN: 0975-5241 (Online)

Revised: 10.09 .2021
Accepted: 09.10.2021
Published: 03.01 .2022 
cal Congenital Heart Disease in neonate may present with cyanosis, respiratory distress, poor peripheral perfusion, difference in pulses (arm vs. leg), hyperactive precordium, abnormally heart sound, prominent heart murmur, Shock and unexplained metabolic acidosis and often these features are difficult to identify underlying cause. ${ }^{4}$ Several tools are regularly used to identify infants who have heart defects. Prenatal ultrasounds performed at 18-20 weeks of pregnancy can reveal anatomical abnormalities. After birth, Physical examination by clinician helps to diagnose CHD along with additional tests like chest radiographs, echocardiograms and pulse oximetry. ${ }^{5}$ Although prenatal ultrasounds and postnatal physical exams successfully detect many heart defects, they are not sufficient to diagnose all cases of CCHD. Postnatally, $20-30 \%$ of CCHD are still missed by physical examination, as symptoms often occur later, when the ductus arteriosus closes. ${ }^{6}$ Murmurs are not always present with CCHD, and may occur in up to $60 \%$ of healthy newborns. ${ }^{7}$ Also, it has been shown that assessment of cyanosis is unreliable for detecting hypoxaemia. ${ }^{8}$ So screening is necessary for early detection and early treatment of these conditions. New research suggests that when all infants are screened using pulse oximetry in conjunction with routine practices, CCHD can be detected in over $90 \%$ of newborns (American Heart Association updates 2013). ${ }^{3}$ Pulse oximetry (PO) is a widely available, accurate method to objectively quantify oxygen saturations ( $\mathrm{SpO} 2)$, and thereby identify the clinically undetectable hypoxaemia that occurs in the majority of neonates with CCHD. ${ }^{9}$ Pulse oximetry is a low-cost, non-invasive and painless bedside diagnostic test that can be completed by in as little as 45 to 60 seconds. It can detect mild hypoxemia, which is characteristic for many forms of CCHD, and those may not be recognized by clinical examination. ${ }^{10}$ When the screening is suggestive of having possibility of CCHD additional testing can be completed. ${ }^{11}$ The American Heart Association (AHA), the American Academy of Pediatrics (AAP), and the American College of Cardiology Foundation (ACCF) recently outlined commendations for a standardized pulse oximetry screening approach and diagnostic follow-up for CCHD (American Heart Association Fact Sheet 2013). ${ }^{3}$ Due to variation in presentation of CCHD, many defects may not be identified and infants may be discharged from the hospitals before signs of disease are detected. So pulse oximetry screening may be helpful for early detection of CCHD. But there is paucity of this type of study in Bangladesh. So the study was conducted to see the role of pulse oximeter as early screening tool for diagnosing CCHD in newborns.

\section{MATERIALS AND METHODS}

This Prospective study was conducted at the department of Neonatology and Department of Obstetrics and Gynecology, Bangabandhu Sheikh Mujib Medical University, Shahbag,
Dhaka, Bangladesh from May 2016 to May 2017 after approval from institutional review board. Neonates were excluded with life-threatening congenital anomalies other than cardiac disease, severe cardio-respiratory depression and required surgical management other than cardiac disease. After taking written informed consent from the parents/guardians, there was a face-to-face interview with the mother or caregivers. A thorough history of these newborn including general information, demographic and socioeconomic information as well as information to facilitate follow-up contact was taken. The infant's medical records was reviewed to identify the risk factors of CHD and recorded in a data collection form. Pulse oximetry screening was conducted by a team of investigators (doctors) in postnatal ward, labor room, postoperative ward and neonatal intensive care unit.

All investigators were demonstrated properly for screening and they were blinded regarding antenatal Echocardiography report. Pulse oximetry testing of the right hand and either any of one foot was performed by investigator in all infants by using pulse oximeter (model- OxiMax N-560 Guide, Korea). Proper care was taken to rule out any interference with pulse oximetry like agitation of the infant, proper placement the probe, human error or equipment malfunction. The test was performed in infant less than 24 hours of age. If the newborn's oxygen saturation is $>95 \%$ in either extremity, with a $<3 \%$ difference (Upper and lower extremity), he or she was considered to pass the screening test (Negative Screening) and due to unavailability of bedside Echocardiography machine no additional evaluation was done unless signs or symptoms of CHD were presented. If the newborn's oxygen saturation is $<90 \%$ irrespective of gestational age in either the hand or foot, and the oxygen saturations are $90-<95 \%$ in both the hand and foot or there is a $>3 \%$ difference between the two on three measurements each separated by one hour the newborn was referred for additional evaluation (Positive screening) by Echocardiography. After collection, Data were calculated manually. Ethically approved by the department and ethical clearance number BSMMU-2017/3370.

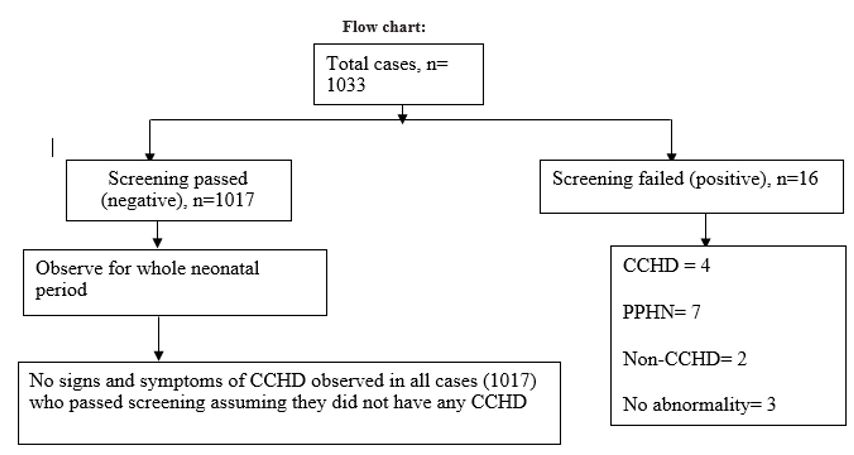

Figure 1: Flow chart of early detection of Critical Congenital Heart Disease in Newborn patients. 


\section{RESULTS}

Among 1033 screened babies, male babies were 504 (48.7\%) and female babies were 529 (51.2\%). Most of them were delivered by lower uterine caesarean section 756 (73.1\%). Categorical distributions of gestational age showed two-third of newborn were term 479 (46.4\%). In birth weight category $503(48.6 \%$ ) had birth weight between $2500 \mathrm{~g}-<4000 \mathrm{~g}$ (Table -1). In this study $572(55.2 \%)$ mothers were between $20-30$ years of age. Parental consanguinity was present in $26(2.5 \%)$ cases. Maternal diabetes mellitus were found in 265 (25.6\%) of mothers and family history of heart diseases was found in $219(21.2 \%)$ cases (Table -2). Among screened 1033 newborns abnormal screening rate was found $16(1.5 \%)$ cases and $4(25 \%)$ newborn babies were having critical congenital heart diseases out of 16 abnormal screened babies and there is no $(100 \%)$ CCHD diagnosed cases who passed screening (Table -3). On Echocardiographic findings, among 16 positive screened babies there were $4(25 \%)$ Critical congenital heart diseases, $2(12.5 \%)$ were non-critical congenital heart diseases, 7 (43.75\%) were PPHN, 3 (18.75\%) had no abnormality (Table -4$)$. The present study found the sensitivity, specificity, positive predictive value, negative predictive value of the Pulse Oximetry screening was $100 \%$, 98.8\%, $25 \%, 100 \%$ respectively (Table -5 ).

\section{DISCUSSION}

Congenital heart diseases are fatal if prompt medical or surgical intervention is not provided. Early detection of congenital heart disease enables for prompt intervention which may save patient's life. Pulse oximetry (PO) screening for critical congenital heart defects (CCHD) has been studied extensively and is being increasingly implemented worldwide. In this study, we examined the utility of pulse oximetry as a screening test for the detection of critical congenital heart disease in newborns. An ideal screening test should detect the latent or early symptomatic period of a disease when early treatment can prevent progression and better outcome. Present study was carried out with screening time within 24 hours of age, on a total of 1033 neonates in department of neonatology and department of Obstetrics and Gynecology, Bangabandhu Sheikh Mujib Medical University, Dhaka, Bangladesh. A meta-analysis demonstrated a significantly lower false positive rate when the screening was performed $\geq 24 \mathrm{~h}$ after birth than when it was done before $24 \mathrm{~h}$; this reduction did not compromise test sensitivity; the sensitivity of the test was moderate overall. ${ }^{12}$ Ewer et al. ${ }^{13}$ showed the highest sensitivity if screening took place 6-12 $\mathrm{h}$ after birth, but specificity was the highest at $0-6 \mathrm{~h}$ after birth. In a large Chinese study, the false positive rate was higher when screening was performed at 6-24 $\mathrm{h}$ after birth $(0.55 \%)$ compared with $25-48(0.29 \%)$ and $9-72(0.26 \%)$ $\mathrm{h}$ after birth, but sensitivity was $10 \%$ higher at $6-24 \mathrm{~h} \cdot{ }^{14} \mathrm{In}$ this study we documented both preductal and postductal measurement. The meta-analysis showed no difference in accuracy between only post-ductal versus combined measurements, but certain left outflow tract obstructions might be missed with post-ductal measurements alone. ${ }^{12}$ However, Ewer et al. ${ }^{13}$ and de-Wahl Granelli et al. ${ }^{15}$ observed that adding a pre-ductal measurement also increased the false positive rate. $95 \%$ oxygen saturation level was used as a cut-off value in this study, at which pulse oximetry screening has the best overall performance and $>3 \%$ difference of saturation between both limbs. Arlettaz et al. ${ }^{15}$ showed the sensitivity and specificity remained quite stable using a cut-off ranging from $92 \%$ to $95 \%$, whereas a cut-off below $92 \%$ led to a rapid decrease of sensitivity. Ewer et al. ${ }^{13}$ defined $\mathrm{SpO} 2<95 \%$ in either limb or a difference of $>2 \%$ between the limbs as abnormal. In their study, the false positive rate would have been reduced from $0.8 \%$ to $0.5 \%$ if they had used a difference of $>3 \%$ in both limbs. ${ }^{15}$ In this study we found positive screening case $16(1.2 \%)$ out of 1033 cases and $4(25 \%)$ cases had CCHD of that positive screening case. Ewer et al. ${ }^{13}$ got $0.97 \%$ positive screening and out of them $10.16 \%$ CCHD, Arlettaz et al. ${ }^{16}$ found $0.7 \%$ positive screening cases and $63 \%$ CCHD among positive screening, Hoke et al. ${ }^{17}$ got $1.9 \%$ failed screening among them $7 \%$ had CCHD. Richmond et al. ${ }^{18}$ found $1.13 \%$ positive screening and of them $12.5 \%$ had CCHD.In this study, the positive cases were diagnosed as double outlet right ventricle (DORV), Tetralogy of fallot (TOF), pulmonary stenosis (PS) and Transposition of great arteries (TGA). Arlettaz et al. ${ }^{16}$ found TGA, HLHS, DORV, critical PS; Hoke et al. ${ }^{17}$ found CoA, TGA, PS, TOF; Bakr et al. ${ }^{19}$ found TAPVR, PA, TA where we found DORV, TGA, which is quite similar to our study. Pulse oxymetry can also detect other causes of hypoxaemia, including infections and pulmonary/respiratory disorders. Although detection of these conditions is currently considered as false positives, it is important to detect them early, so treatment can be started before deterioration occurs with increased risk of death, morbidity and longer hospitalization. Narayen IC, et al. ${ }^{20}$ showed PPHN is the most common differential diagnosis of positive screening which similar to our finding where PPHN was diagnosed in 7 cases out of 16 positive cases. In the present study, Pulse oxymetry screening in order to detect cyanotic CHD shows a very good sensitivity $(100 \%)$, specificity $(96.8 \%)$ and NPV (100\%), but the PPV $(25 \%)$ is less than optimal. A sensitivity of $100 \%$ in the detection of cyanotic CHD has been previously reported by others Arlettaz et al. ${ }^{16}$, Hoke et al. ${ }^{17}$, Bakr et al. ${ }^{19}$ Sendelbach et al. ${ }^{21}$ In our study, PPV (25\%) is not optimal. Richmond et al. ${ }^{18}$ and Reich ${ }^{22}$ found almost similar PPP to our study $15 \%$ and $33.3 \%$ respectively. In this study there were some limitations as it was conducted in single center, cases were taken before 24 hours of age, and due to resource limitation Echocardiography cannot be done in all negative screening 
cases. We recommend for further prospective studies with larger sample size and Echocardiography for true diagnosis.

\section{CONCLUSION}

The present study concluded that with this high sensitivity, specificity and negative predictive value Pulse oximetry is safe, feasible and can be used to screen for critical congenital heart disease. It would be an attainable noninvasive method to detect the congenial heart disease along with the physical examination in newborn.

\section{Conflict of interest: Nil}

\section{Source of Funding: Nil}

Author contributions: Conceptualization:M. A. Mannan, Amlendra Yadav, Tareq Rahman, Ismat Jahan, Sadeka Choudhury Moni, Mohammad Abul Khayer, Mohammad Kamrul Hassan Shabuj, Sanjoy Kumer Dey, Mohammod Shahidullah.

\section{Writing-original draft: $M$. A. Mannan}

Writing-review \& editing: M. A. Mannan, Amlendra Yadav

All authors contributed to the final version of the manuscript.

All authors read and approved the final manuscript.

Acknowledgment: Care providers of Obs and Gynae department and NICU at Bangabandhu Sheikh Mujib Medical University, Shahbag, Dhaka, Bangladesh

Ethical Clearance: Ethically approved by the department.

\section{REFERENCES}

1. Hoffman JI, Kaplan S et al. The incidence of congenital heart disease. J Am Coll Cardiol 2002; 39:1890-900.

2. American Heart Association, Congenital Cardiovascular Defects, Statistical Fact Sheet 2013 Update.

3. Gomella, TL, Cunningham, MD, Eyal, FG and Tuttle, DJ, 2013, Neonatology Management, Procedure, On-Call Problem, Diseases and Drugs, $7^{\text {th }}$ edn, McGraw Hill education, New York.

4. Fixler DE, Xu P, Nembhard WN,. Age at referral and mortality from critical congenital heart disease. Pediatrics 2014; 134:e98105.

5. Frank T R, Cornelia W, Schneider P, Mockel A,. Effectiveness of neonatal pulse oximetry screening for detection of critical congenital heart disease in daily clinical routine - results from a prospective multicenter study, Eur J Pediatr (2010) 169:975981.

6. Gorska-Kot A, Blaz W, Pszeniczna E,. Trends in diagnosis and prevalence of critical congenital heart defects in the Podkarpacie province in 2002-2004, based on data from the Polish Registry of Congenital Malformations. J Appl Genet, 2006; 47:191-4.

7. Meberg A, Andreassen A, Brunvand L,. Pulse oximetry screening as a complementary strategy to detect critical congenital heart defects. Acta Paediatr, 2009; 98:682-6.

8. Valmari P. Should pulse oximetry be used to screen for congenital heart disease? Arch Dis Child Fetal Neonatal Ed 2007; 92:F219-224.

9. O’Donnell CP, Kamlin CO, Davis PG, Clinical assessment of infant colour at delivery. Arch Dis Child Fetal Neonatal Ed 2007; 92:F465-467.

10. Shah F, Chatterjee R, Patel P C, KunkulolR. Early detection of critical congenital heart disease in newborns using pulse oximetry screening, Int J Med Res Health Sci. 2015; 4(1): 78-83

11. Congenital Heart Disease Screening Program Toolkit, 2ndedition, Children's National Medical Center's Congenital Heart Disease Screening Program.

12. Thangaratinam S, Brown K, Zamora J,. Pulse oximetry screening for critical congenital heart defects in asymptomatic newborn babies: a systematic review and meta-analysis. Lancet 2012; 379:2459-64.

13. Hoke TR, Donohue PK, Bawa PK, Oxygen saturation as a screening test for critical congenital heart disease: a preliminary study. Pediatr Cardiol 2002; 23: 403-09.

14. Richmond S, Reay G, Abu-Harb M, Routine pulse oximetry in the asymptomatic newborn. Arch Dis Child FetNeonatal Ed 87:F83-F88

15. Ewer AK, Furmston AT, Middleton LJ, Pulse oximetry as a screening test for congenital heart defects in newborn infants: a test accuracy study with evaluation of acceptability and costeffectiveness. Health Technol Assess 2012; 16: v-xiii, 1-184.

16. Bakr AF, Habib HS, Combining pulse oximetry and clinical examination in screening for congenital heart disease. Pediatr Cardiol 2005; 26: 832-35.

17. Arlettaz R, Bauschatz AS, Mönkhoff M, Essers B, Bauersfeld $\mathrm{U}$, The contribution of pulse oximetry to the early detection of congenital heart disease in newborns. Eur J Pediatr 2006 Feb 1; 165(2):94-8.

18. Sendelbach DM, Jackson GL, Lai SS,. Pulse oximetry screening at 4 hours of age to detect critical congenital heart defects. Pediatrics 2008; 122:e815-820.

19. Brown K L, Ridout D A, Hoskote A, Verhulst L, Ricci M, Bull $\mathrm{C}$ et al. Delayed diagnosis of congenital heart Disease worsens preoperative condition and outcome of surgery in neonates. Heart 2006; 92:1298-302.

20. Cora P, Elizabeth A, Tiffany R C, Matthew E. O, Cynthia H. C, David E. F, Suzan L, Gary M. S, Suzanne M. G et al. Estimation of the Potential Impact of Proposed Universal Screening Using Pulse Oximetry, JAMA Pediatr. 2014-168(4):361-370.

21. IIona N, Nico B, Andrew E, Maximo V, Paolo M, Arjan B T P, et al. Aspects of pulse oximetry screening for critical congenital heart defects: when, how and why? Arch Dis Child Fetal Neonatal Ed 2015; 0:F1-F6.

22. Kochilas LK, Lohr JL, Bruhn E, Implementation of critical congenital heart disease screening in Minnesota. Pediatrics 2013; 132:e587-594. 
Table 1: Baseline characteristics of the study group ( $\mathrm{N}=1033)$

\begin{tabular}{|c|c|c|}
\hline Characteristics & Frequency & Percent \\
\hline \multicolumn{3}{|l|}{ Sex } \\
\hline Male & 504 & 48.7 \\
\hline Female & 529 & 51.2 \\
\hline \multicolumn{3}{|l|}{ Gestational Age } \\
\hline Term & 479 & 46.4 \\
\hline $34-<37$ weeks & 218 & 21.1 \\
\hline $32-<34$ weeks & 254 & 24.5 \\
\hline $28-<32$ weeks & 69 & 6.7 \\
\hline$<28$ weeks & 13 & 1.2 \\
\hline \multicolumn{3}{|l|}{ Mode of Delivery } \\
\hline LUCS & 756 & 73.1 \\
\hline NVD & 277 & 26.8 \\
\hline \multicolumn{3}{|l|}{ Birth weight } \\
\hline$<1500 \mathrm{~g}$ & 214 & 20.7 \\
\hline $1500 g-<2500 g$ & 308 & 29.8 \\
\hline $2500 \mathrm{~g}-<4000 \mathrm{~g}$ & 503 & 48.6 \\
\hline$>4000 g$ & 8 & 0.7 \\
\hline
\end{tabular}

Table 2: Baseline Characteristics of the Mothers $(\mathrm{N}=1033)$

\begin{tabular}{|c|c|c|}
\hline Characteristics & Frequency & Percent \\
\hline \multicolumn{3}{|l|}{ Maternal Age } \\
\hline$<20$ years & 238 & 23 \\
\hline $20-<30$ years & 571 & 55.2 \\
\hline $30-<40$ years & 221 & 21.3 \\
\hline$>40$ years & 3 & 0.3 \\
\hline \multicolumn{3}{|l|}{ Consanguinity } \\
\hline Present & 26 & 2.5 \\
\hline Absent & 1007 & 97.5 \\
\hline \multicolumn{3}{|c|}{ Maternal Diabetes mellitus } \\
\hline Present & 265 & 25.6 \\
\hline Absent & 768 & $74 \cdot 4$ \\
\hline \multicolumn{3}{|c|}{ Family H/O Heart Disease } \\
\hline Present & 219 & 21.2 \\
\hline Absent & 814 & 78.8 \\
\hline \multicolumn{3}{|c|}{ H/O Maternal Lupus } \\
\hline Present & 8 & 0.8 \\
\hline Absent & 1025 & 99.2 \\
\hline \multicolumn{3}{|c|}{ H/O Radiation exposure } \\
\hline Present & 240 & 23.2 \\
\hline Absent & 793 & 76.7 \\
\hline
\end{tabular}


Table 3: Pulse oximetry screening findings $(\mathrm{N}=1033)$

\begin{tabular}{lllllll} 
Screening & Frequency & Percent & $\begin{array}{l}\text { CCHD } \\
\text { Frequency }\end{array}$ & Percentage & $\begin{array}{l}\text { No CCHD } \\
\text { Frequency }\end{array}$ & Percentage \\
Positive & 16 & 1.5 & 4 & 25 & 12 & 75 \\
Negative & 1017 & 98.5 & 0 & 0 & 1017 & 100 \\
\hline
\end{tabular}

Table 4: Echocardiography findings of Positive screening ( $\mathrm{N}=16)$

\begin{tabular}{lcc} 
Diagnosis & Numbers & \\
Tetralogy of fallout & 1 & \\
Double outlet right ventricle & 1 & CCHD \\
Pulmonary stenosis & 1 & \\
Transposition of great arteries & 1 & Non-CCHD \\
AVSD & 1 & \\
VSD & 1 & \\
PPHN & 7 & \\
No abnormality & 3 & \\
\hline
\end{tabular}

Table 5: Sensitivity, specificity, positive predictive value and negative predictive value $(\mathrm{N}=1033)$

\begin{tabular}{llll} 
Test & Disease $($ CCHD $)$ & No Disease & \\
Positive & True positive $=4$ & False positive $=12$ & Total test positive $=16$ \\
Negative & False negative $=0$ & True negative $=1017$ & Total test negative $=1017$ \\
& Total disease $=4 / 1033(1.04 \%)$ & Total normal $=1029$ & Total population $=1033$ \\
\hline
\end{tabular}

Sensitivity $=$ true positive $/($ true positive + false negative $)=4 / 4+0=1(100 \%)$, Specificity $=$ true negative $/$ (true negative + false positive $)=369 / 369+12=0.988=98.8 \%, \mathrm{PPV}=$ true positive $/($ true positive + false positive $)=4 / 4+12=0.25=25 \%, \mathrm{NPV}=$ true negatives $/($ false negative + true negative $)=369 / 369+0=1=100 \%$. 